\title{
Prophylaxis of \\ cytomegalovirus in renal transplant recipients
}

\author{
AlLAN S MACDONALD, FrCSC, DAVID L NICOL, FRASC, PHILIP BELITSKY, FRCSC, \\ SPENCER LEE, PHD
}

\begin{abstract}
as MacDonald, DL Nicol, P Belitsky, S Lee. Prophylaxis of cytomegalovirus in renal transplant recipients. Can J Infect Dis 1993:4(Suppl C):51C-57C. The incidence and outcome of cytomegalovirus (CMV) infection and disease is compared in renal transplant recipients in relation to the use of prophylaxis with high titre anti-CMV immunoglobulin. Seventy-three CMV-negative recipients (R-) who received kidneys from CMV-positive donors (D+) were given prophylactic CMV hyperimmune globulin intravenously at three-week intervals to six months. They also received three months of oral low dose acyclovir as did the remaining 288 patients who did not receive hyperimmune globulin. There was a low incidence of CMV disease which did not differ between groups (D+R-, 10\%; D+R+, 5.5\%, D-R+, 7\%; D-R-, 0.8\%). The major risk factor was the use of OKT3 to treat rejection. CMV disease was seen in $22 \%$ of this group (11 of 50), compared with only $2 \%$ (seven of 311 ) of those not requiring OKT3. There was only one CMV-related death, but patients with CMV disease had a reduced graft survival rate (62\% versus $90 \%)$. CMV hyperimmune globulin added to acyclovir appears to reduce the incidence of CMV disease in high risk renal recipients (D+R-) in the lower risk groups.
\end{abstract}

Key Words: Acyclovir, CMV hyperimmune globulin, Cytomegalovirus, Renal transplant

\section{Prophylaxie du cytomégalovirus chez les receveurs de transplantation rénale}

RÉSUMÉ: L'incidence et les conséquences de l'infection à cytomégalovirus (CMV) sont comparées chez des receveurs de transplatation rénale relativement à l'emploi d'une prophylaxie à base d'immumoglobuline anti-CMV à titrage élevé. Soizante-treize receveurs CMV-négatifs (R-) qui ont reçu des reins de donneurs CMV-positifs $(\mathrm{D}+)$ ont reçu un traitement prophylactique intravenineux à base de globuline de CMV hyperimmune à des intervalles de trois semaines durant six mois. Ils ont reçu aussi durant trois mois de l'acyclovir à faible dose, tout comme les 288 autres patients non placés sous globuline hyperimmune. L'incidence d'infection à CMV a été faible chez les deux groupes $(\mathrm{D}+\mathrm{R}-, 10 \%$; $\mathrm{D}+\mathrm{R}+, 5,5 \%$; D-R+, 7\%, D-R-, $0,8 \%$ ). Le principal facteur de risque a été le recours au OKT3 pout traiter les rejets. La maladie à CMV a été observée chez $22 \%$ des sujets de ce groupe (11 sur 50), comparé à $2 \%$ seulement (sept sur 311 ) chez qui l'OKT3 n'a pas été nécessaire. Un seul décés est survenu en rapport avec le CMV, mais les patients atteints de maladie au CMV ont présenté une baisse du taux de survie lié à la greffe (62\% contre $90 \%$ ). La globuline hyperimmune ajoutée à l'acyclovir semble réduire l'incidence de maladie à CMV chez les receveurs de transplation rénale à haut risque $(\mathrm{D}+\mathrm{R}-)$ dans les groupes les moins à risque.

Kidney Transplant Service, Victoria General Hospital, and Department of Microbiology, Dalhousie University, Halifax, Nova Scotia

Correspondence and reprints: Dr AS MacDonald, Dickson Centre, Victoria General Hospital, 1278 Tower Road, Halifax, Nova Scotia B3H 2 Y9 
$\mathrm{C}$ YTOMEGALOVIRUS (CMV) CONTINUES TO BE AN IMPORTANT cause of morbidity and graft loss in renal transplant recipients. Most commonly, quiescent virus is reactivated in previously infected patients under the influence of immunosuppression or is transmitted in the graft from a seropositive donor to a seronegative recipient. This latter group is most at risk because de novo infections in immunocompromised hosts are usually more severe and more likely to be lethal. Transplant patients developing CMV-induced disease are also more likely to suffer loss of their grafts.

A variety of strategies has been employed to minimize the risks of CMV in transplant programs. A common approach is to avoid grafting from CMV seropositive donors to CMV seronegative recipients. Although this eliminates the group at most risk, it does not address the problem of reactivation disease. It also decreases the opportunity for seronegative patients to receive a graft.

Based on the observation that prophylactic treatment of transplant recipients with acyclovir to prevent herpesvirus infections is accompanied by a reduction in CMV disease, we have elected to give this agent to all our kidney recipients. In addition, the high risk group, ie, seronegative recipients of grafts from seropositive donors, also received intravenous immunoglobulin with a high titre of antibodies against CMV.

This report describes the results of this strategy on the incidence and severity of CMV infection and disease in patients receiving kidney transplants.

\section{PATIENTS AND METHODS}

Patient population: All 355 patients who received 361 renal transplants between January 1987 and July 1991 were included. The patients were divided into four groups based on the CMV status of donor and recipient before transplantation, ie, $\mathrm{D}+/ \mathrm{R}-(\mathrm{n}=73), \mathrm{D}+\mathrm{R}+(\mathrm{n}=91)$, $\mathrm{D}-/ \mathrm{R}+(\mathrm{n}=74)$ and $\mathrm{D}-/ \mathrm{R}-(\mathrm{n}=123)$. Other donor and recipient characteristics were also compared (Table 1).

Anti-CMV hyperimmune globulin (CMV-HIG) (Cytomegalovirus-Hyperimmunoglobulin IV, Immuno, Vienna) was administered intravenously to all $\mathrm{D}+/ \mathrm{R}-$ patients. CMV-HIG is a virus-inactivated, lyophilized concentrate of pooled human plasma obtained from donors reactive for CMV, with a standardized reconstituted concentration of anti-CMV antibodies of $50 \mathrm{U} / \mathrm{mL}$, according to the reference preparation of the Paul Ehrlich Institute. Using a standardized complement fixation antibody test, the preparation was found to contain a CMV antibody titre of $1: 128$. Patients were given $1 \mathrm{~mL} / \mathrm{kg}$ preoperatively and then at three-week intervals for six months. The six-month time was arbitrary, but was felt to encompass the major at-risk period and overlaps the three months of acyclovir.

All patients, regardless of CMV status, received low dose oral acyclovir $600 \mathrm{mg} /$ day in divided doses for three months unadjusted for level of renal function.
CMV serology: Pretransplant donor and recipient CMV status was determined using a passive latex agglutination assay (CMV Scan, Becton Dickinson). Post-transplant anti-CMV titres from $\mathrm{D}+/ \mathrm{R}-$ patients were routinely determined using a standardized complement fixation antibody test on samples obtained immediately before each CMV-HIG treatment and again at one year. Other patients had similar post-transplant CMV serology performed only if clinical disease was suspected. The serology did not distinguish between immunoglobulin (Ig) G and IgM. Seroconversion was therefore defined as seropositive reactivity six to 12 months posttransplantation in recipients who were previously CMV seronegative, to exclude contamination with passively administered antibody.

CMV disease diagnosis and treatment: All patients who developed a fever or in whom there was a clinical suspicion of CMV disease were investigated by serial CMV serology. This consisted of a complement fixation antibody test and serial cultures for CMV in urine, blood buffy coat specimen and sputum, using the shell vial culture technique (1). If kidney biopsy material was available, it was stained for CMV inclusions.

Clinical CMV disease was treated by supportive measures, antibiotic therapy against secondary infections and reduction of immunosuppression. Since January 1990, patients with disease have been treated with intravenous ganciclovir at a dosage of $10 \mathrm{mg} / \mathrm{kg} /$ day for 14 days, adjusting the dose according to renal function.

Definitions: CMV infection was defined as any one of: seroconversion of previously CMV-negative patient; a fourfold or greater rise in the serum antibody titre in a previously CMV-positive patient; culture of the virus from blood or other body fluids; or the presence of CMV inclusion bodies in histological sections of biopsy specimens.

CMV disease was defined as any combination of features defined under CMV infection plus clinically significant signs and/or symptoms of tissue invasion. Patients were classified according to severity of their CMV disease as follows:

- Moderate: one or more of: anemia; thrombocytopenia; leukopenia; hepatitis; pneumonitis; gastrointestinal ulceration; neurological symptoms; deteriorating renal function; or any bacterial, fungal or protozoal superinfection.

- Severe: CMV pneumonitis requiring mechanical ventilation, or gastrointestinal ulceration requiring operative intervention.

- Lethal: Death occurring in association with any CMV infection, whether or not it was the direct cause of death.

Graft failure was defined as a return to dialysis or retransplantation.

Immunosuppressive therapy: Patients received cyclosporine A (CsA)-based immunosuppression according to established regimens or study protocols in place at 
TABLE I

Characteristics of patients reviewed according to donor/recipient cytomegalovirus status

\begin{tabular}{|c|c|c|c|c|}
\hline Group & $D+/ R-(n=73)$ & $D+/ R+(n=91)$ & $D-/ R+(n=74)$ & $D-/ R-(n=123)$ \\
\hline Living related donor & $24(33 \%)$ & $28(31 \%)$ & $11(15 \%)$ & $41(33 \%)$ \\
\hline Cadaver donor & $49(67 \%)$ & $63(69 \%)$ & $63(85 \%)$ & $82(67 \%)$ \\
\hline Previous transplant & $8(11 \%)$ & $15(16 \%)$ & $15(20 \%)$ & $15(12 \%)$ \\
\hline Plasma renin activity $>40$ & $8(11 \%)$ & $14(15 \%)$ & $16(22 \%)$ & $26(21 \%)$ \\
\hline Diabetes & $20(27 \%)$ & $24(26 \%)$ & $13(18 \%)$ & $26(21 \%)$ \\
\hline Delayed function & $17(23 \%)$ & $19(20 \%)$ & $15(20 \%)$ & $19(15 \%)$ \\
\hline CsA/prednisone & $11(15 \%)$ & $12(13 \%)$ & $5(7 \%)$ & $13(11 \%)$ \\
\hline CSA/AzA & $1(1 \%)$ & & & \\
\hline AzA/prednisone & & $1(1 \%)$ & & \\
\hline ALG/CsA/prednisone & & & $1(1 \%)$ & \\
\hline *OKT3 & $10(14 \%)$ & $12(13 \%)$ & $15(20 \%)$ & $13(11 \%)$ \\
\hline
\end{tabular}

-Denotes patients with steroid-resistant rejections treated with OKT3 for 10 to 14 days; ALG Antilymphocyte globulin: AzA Azathioprine; CsA Cyclosporine A; D Donor: OKT3 OKT3 monoclonal antibody: R Recipient

the time (2). Details of immunosuppression are summarized in Table 1.

All but three patients received prednisone and CsA. CsA was initially administered by continuous intravenous infusion at a dosage of 3 to $4 \mathrm{mg} / \mathrm{kg} /$ day for five days and subsequently orally at $10 \mathrm{mg} / \mathrm{kg} /$ day in two divided doses. Dosages were adjusted to maintain target radioimmunoassay whole-blood trough levels (Incstar) of approximately $300 \mathrm{mg} / \mathrm{mL}$ for the first 180 days and 100 to $200 \mathrm{mg} / \mathrm{mL}$ thereafter, depending on efficacy and nephrotoxicity. Methylprednisone $500 \mathrm{mg}$ was given intravenously at transplantation followed by oral prednisone ( $1 \mathrm{mg} / \mathrm{kg} /$ day) which was tapered to be discontinued at about 105 days. All patients received azathioprine $2 \mathrm{mg} / \mathrm{kg}$ intravenously during surgery, then $1.5 \mathrm{mg} / \mathrm{kg} /$ day orally until it was discontinued after 30 days. Patients who had received a transplant previously or who received a 'marginal' kidney (donor age less than five years or more than 60 years, or extended ischemia) received a polyclonal equine antilymphocyte globulin (ALG) (Lymphoglobulin, Merieux, Paris, France) $0.5 \mathrm{~mL} / \mathrm{kg} /$ day intravenously to a maximum of $35 \mathrm{~mL} /$ day commencing immediately following transplantation. ALG was continued until serum creatinine fell below $300 \mu \mathrm{mol} / \mathrm{L}$, at which time intravenous CsA was commenced as above. In addition, 57 recipients of first cadaver kidney transplants also received ALG as above before CsA as part of a randomized study comparing ALG with CsA for induction immunosuppression (2). In total, 127 patients received ALG, with a mean duration of therapy of three days. Rejection episodes were all confirmed histologically by fine needle aspiration biopsy and/or minicore biopsy. Initial antirejection therapy consisted of a rapidly tapering high dose oral prednisone pulse (500 mg, $250 \mathrm{mg}, 125 \mathrm{mg}$, $75 \mathrm{mg}, 50 \mathrm{mg}, 40 \mathrm{mg}, 30 \mathrm{mg}, 20 \mathrm{mg}$ on successive days) added to the maintenance prednisone regimen. In the absence of a clinical and biochemical response by day 5 of antirejection treatment, biopsy was repeated to determine the cause of unresponsiveness. Histologically confirmed steroid-resistant rejection was treated with OKT3 monoclonal antibody (Orthoclone, Ortho), $5 \mathrm{mg} /$ day intravenously for 10 to 14 days, during which time the CsA dose was reduced by 50\%. During the first three days of OKT3 therapy, patients received methyl prednisone intravenously (500 mg, $100 \mathrm{mg}$ and $100 \mathrm{mg}$ ) to minimize early side effects.

\section{RESULTS}

The four groups of patients had similar donor and recipient characteristics and immunosuppression as outlined in Table 1.

\section{Relationship of CMV status to infection and disease:} The incidence of post-transplant CMV infection and disease according to pretransplant donor/recipient CMV serology is shown in Figure 1. The D+/R- group had a greater number of patients with a rise in CMV complement fixation antibody titre posttransplant, both asymptomatic and associated with a transient unexplained fever. Of the patients who demonstrated seroconversion at or before six months, all continued to have positive CMV titres at 12 months. Statistical significance between the groups could not be tested because routine serology was only performed in the $D+/ R-$ group. Among these patients, 38 of 73 (52\%) seroconverted.

Only one of $123 \mathrm{D}-/ \mathrm{R}$ - patients $(0.8 \%)$ developed clinical CMV disease. A significantly higher incidence $(\mathrm{P}<0.05)$ was seen in the three other groups, each of which had a comparable incidence of clinical CMV disease (D+/R-, 10\%; D+/R+, 5.5\%; and D-/R+, 7\%). Disease severity and associated graft loss were likewise similar in these latter three groups (Figure 2). Of the 238 graft recipients in whom either the donor or recipi- 


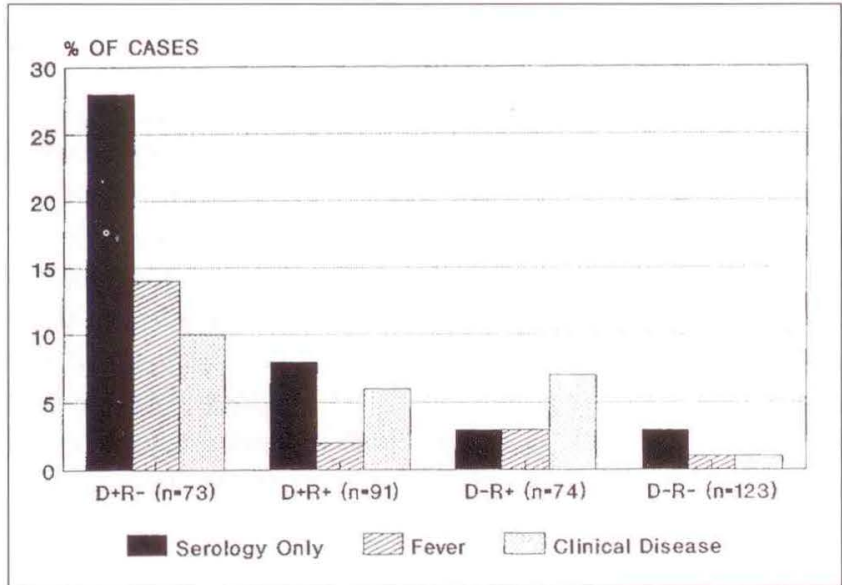

Figure 1) Patterns of post-transplant cytomegalovirus (CMV) infection according to pretransplant donor and recipient $C M V$ serology. Seroconversion is considered the least serious manifestation, and clinical disease the most serious. $D$ Donor; $R$ Recipient

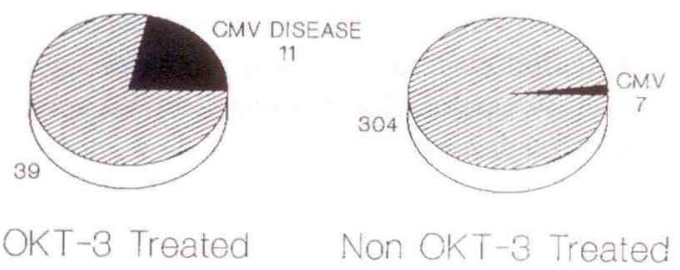

Figure 3) Relationship between OKT3 rescue treatment and cytomegalovirus (CMV) disease

ents had positive serology and who would therefore be considered at risk, only 17 (7\%) developed clinical CMV disease: 13 moderate $(5.4 \%)$; three severe $(1.2 \%)$; and one lethal $(0.4 \%)$. The only CMV-related death was in a D+/R- patient who developed CMV sepsis, despite clearing of the virus with ganciclovir therapy. Of four patients with severe disease, three had pneumonitis requiring ventilatory support, and the fourth had a bowel perforation requiring laparotomy and resection. Of the remaining 13 patient with moderate disease, five developed pneumonitis; five had renal dysfunction or subsequent rejection; two had anemia, leukopenia or thrombocytopenia for which another cause could not be found; and one had hepatitis with fever and a transient elevation in liver enzymes associated with a rise in CMV titres. Fewer than $10 \%$ of patients experienced initial nonfunction of the kidney, equally distributed among the four groups. There was no correlation between risk of CMV disease and initial function.

Use of OKT3 and CMV infection: Of the 18 patients who developed clinical CMV disease, 11 (61\%) had received OKT3 rescue for steroid-resistant or recurrent rejection, including all five who developed severe or

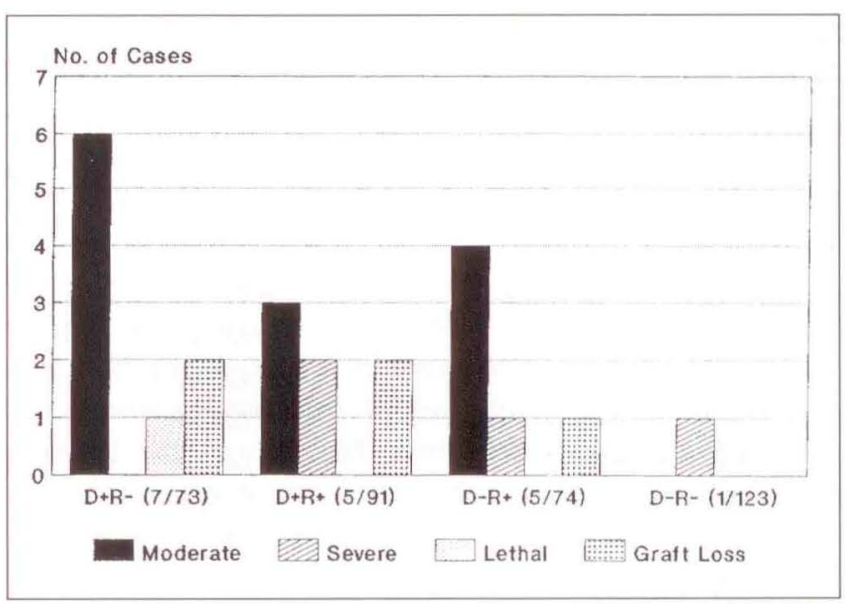

Figure 2) Severity of clinical cytomegalovirus (CMV) disease according to pretransplant donor and recipient $C M V$ serology. $D$ Donor: R Recipient

lethal disease and four of the five (80\%) with CMV-related graft losses. Five of the 18 with clinical CMV disease had no rejection episodes, while the remaining two had a single rejection readily reversed by steroids.

Eleven of 50 patients requiring OKT3 rescue treatment for steroid-resistant rejections developed clinical CMV disease, compared with only seven of 311 patients who did not require OKT3 $(\mathrm{P}<0.001)$ (Figure 3$)$. Of the patients who received OKT3, the prior use of ALG, regardless of duration, did not increase the risk of CMV disease, which occurred in four of 24.

Other viral diseases: No patient developed active herpes simplex or zoster infections, but four patients developed lymphoproliferative disorders probably related to Epstein-Barr virus infection. All four patients had received OKT3 for steroid-resistant rejection, with three receiving prior ALG (of whom two died).

Complications of prophylaxis: No patient developed complications attributable to the use of either acyclovir or CMV-HIG.

Patient and allograft survival: Post-transplant CMV disease was associated with significantly reduced graft survival at one year $(62 \%$ versus $90 \%, \mathrm{P}<0.01)$, but patient survival was similar to that without CMV disease (97\% versus 93\%) (Figure 4). Pretransplant CMV status of donor and recipient, however, did not adversely affect either graft or patient survival (Figures $5,6)$. D+/R-patients actually had better one- and threeyear graft survival than the others $(94 \%$ versus $87 \%$ and $86 \%$ versus $74 \%, \mathrm{P}<0.05$ ).

\section{DISCUSSION}

CMV disease can be transmitted to recipients by the transplanted organ, especially if there is no prior immunity as measured by serum antibody, even in situations where antibody is present. Occasionally, this may be due to virus strain differences. Most commonly, if the patient is seropositive, the occurrence of disease after 


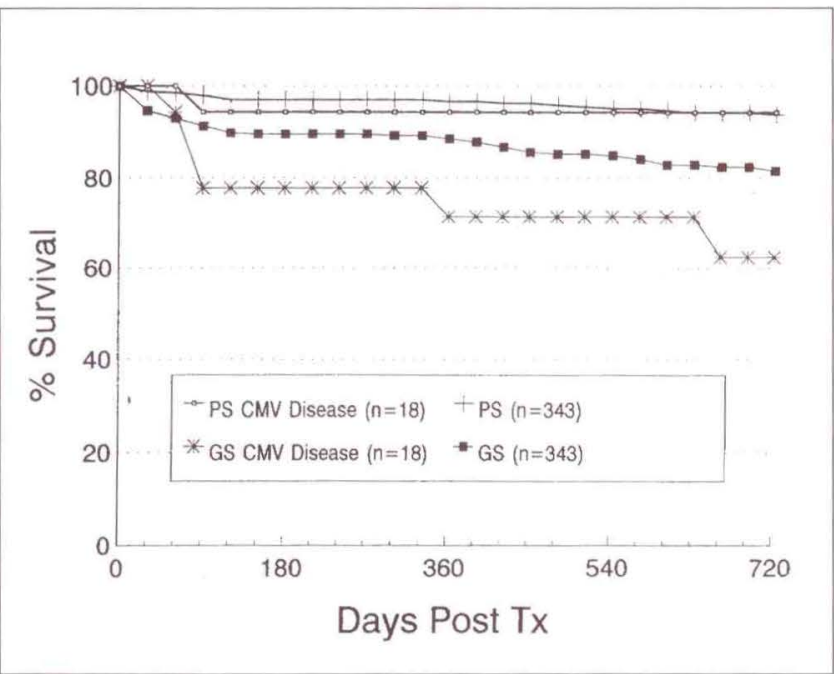

Figure 4) Comparison of graft and patient survival in patients with cytomegalovirus (CMV) disease to concurrent recipients without CMV disease. GS Graft survival; PS Patient survival; Tx Transplant

grafting is due to reactivation of latent recipient virus. It is true, however, that reactivation disease occurs less commonly and is less severe in seropositive recipients than in seronegative recipients given an organ from a seropositive donor. Here seroconversion occurs in 50 to $85 \%$ and disease in 40 to $60 \%$ of recipients (3-9).

Because of the high incidence of disease in the transplant population, a variety of approaches to prophylaxis has been tried. The use of CMV-HIG as a single agent has been reported for a variety of organ transplants. These preparations are made from pools of sera from preselected donors with high titres of CMV antibody which should cover the spectrum of CMV strains. In a prospective randomized trial by Snydman et al (7), the use of CMV-HIG without acyclovir did not alter the overall incidence or onset of CMV infection, but resulted in a threefold reduction in symptomatic infections. In the present study, with a much larger number of patients at risk, CMV seroconversion rates were similar ( $52 \%$ versus $68 \%$ ) but the incidence of CMV disease in D+/R- kidney transplants was less $(10 \%$ versus $20 \%$ ), as was graft loss from CMV ( $3 \%$ versus $17 \%)$.

The combined use of CMV-HIG and low dose acyclovir would therefore appear to inhibit the development of CMV disease in those at risk for primary infection, although it does not prevent seroconversion. Presently the mechanism of action of CMV-HIG in preventing $\mathrm{CMV}$ disease is unclear. Conceivably, CMV-HIG may form immune complexes with CMV, which in turn may augment some or all of the humoral or cell-mediated immune responses provoked by CMV activation as suggested previously $(10,11)$.

Oral acyclovir has also been noted to reduce the incidence of CMV disease following transplantation (12). The authors have used low dose acyclovir, 600

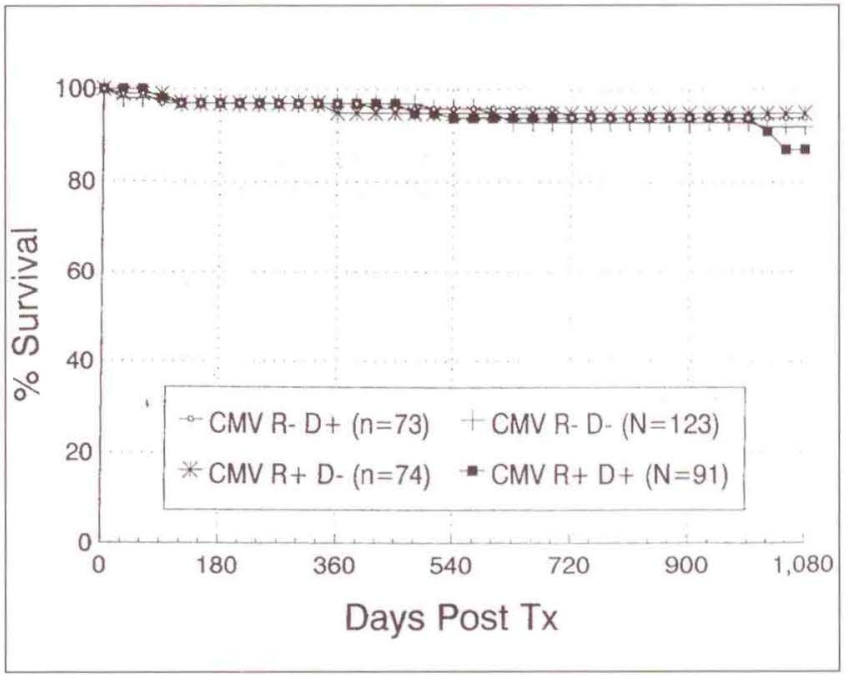

Figure 5) Patient survival with groups based on donor and recipient pretransplant cytomegalovirus (CMV) serology. D Donor; R Recipient: Tx Transplant

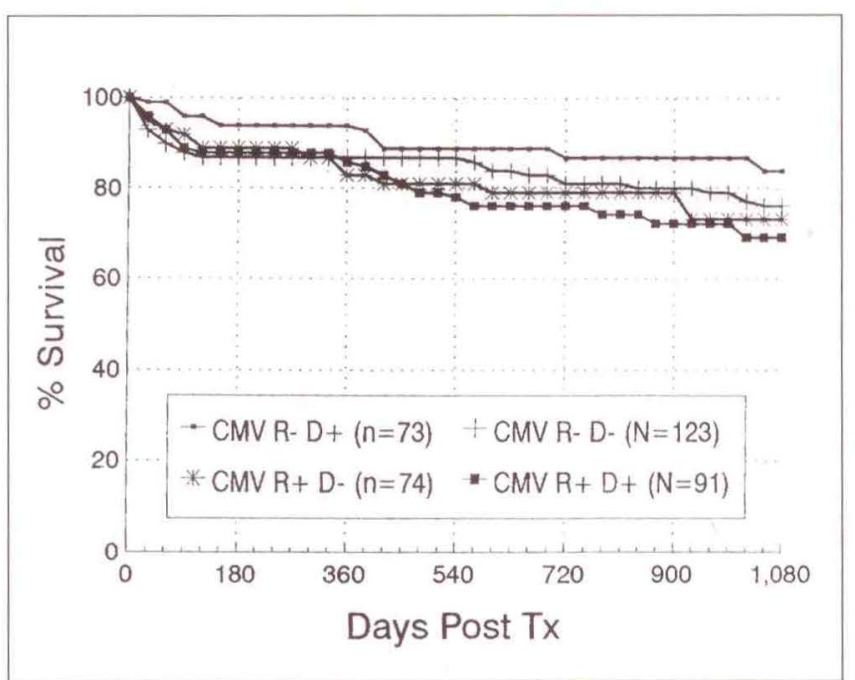

Figure 6) Graft survival with groups based on donor and recipient pretransplant cytomegalovirus (CMV) serology. D Donor: $R$ Recipient; Tx Transplant. $(D+/ R-$ versus $D-/ R-, P$ not significant; $D+/ R$ - versus $D-/ R+, P<0.05 ; D+/ R$-versus $D+/ R+$, $P<0.025)$

$\mathrm{mg} /$ day, initially for herpes simplex virus prophylaxis (13), for which it has been highly effective. Conceivably, the low overall incidence (5\%) of clinical CMV disease in the series under discussion may also be attributed to its use. Balfour at al (12), in a randomized, placebo controlled trial, demonstrated a reduction in CMV disease in renal transplant patients from $29 \%$ in controls to $7.5 \%$ in those receiving high dose oral acyclovir. The authors noted that the doses of acyclovir used in their study, 1800 to $3200 \mathrm{mg} /$ day, resulted in plasma concentrations lower than required for inhibition of CMV in vitro.

The present study suggests an additive affect of acyclovir and CMV-HIG in preventing CMV disease in 
$\mathrm{D}+/ \mathrm{R}-$ renal transplant recipients. The $10 \%$ incidence of CMV disease noted in the group who received both acyclovir and CMV-HIG was lower than the 20\% reported in the studies using either agent alone $(7,12)$. CMV-HIG has been observed to have a synergistic effect against CMV with ganciclovir (14). In treating CMV pneumonitis in bone marrow recipients, a much higher response rate was noted when the two were used together than when either agent was used alone $(15,16)$.

The intensity of immunosuppression contributes to the development of CMV disease although it is less frequent with CsA-based therapy $(5,17)$. CsA may be less suppressive of CMV-specific cytotoxic T cell and natural killer cell responses. In addition, lower doses of corticosteroids are used with CsA-based immunosuppression, and acute rejection episodes requiring additional immunosuppression are less common. Serious CMV disease is observed with much greater frequency in patients receiving antilymphocytic serum preparations (6). In our series, the use of OKT3 in the setting of steroid-resistant rejection was a major risk factor for CMV disease. The incidence of $22 \%$ in patients receiving OKT3 for steroid-resistant rejection compares with rates of 20 to $59 \%$ reported in recent studies $(18,19)$. The fact that prior treatment with ALG did not further increase the risk of CMV disease in our patients was surprising, but in keeping with a recent study by Chiu et al (20). It is not clear whether ALG or OKT3 are equally culpable in predisposing to CMV disease when used alone. Both ALG and OKT3 have been associated with a similar incidence of CMV disease when used for induction of immunosuppression (21). In contrast, when used as rescue therapy for refractory acute myocardial rejection, OKT3 has resulted in significantly more CMV disease and associated morbidity than ALG (22). Experimental evidence also suggests OKT3 may be a specific risk factor for CMV disease. Carrano et al (23) demonstrated that anti-anti-idiotypic antibodies, generated in some renal transplant recipients after receiving OKT3 for rejection, were specifically associated with the appearance of CMV disease. A subsequent study (24) demonstrated structural similarity between the T cell receptor/CD-3 complex and antibodies generated against CMV virion epitopes and may account in part for the association between the use of OKT3 for rescue therapy and CMV disease.

\section{REFERENCES}

1. Gleaves CA, Smith TF, Shuster EA, Pearson GR. Rapid detection of cytomegalovirus in MRC-5 cells inoculated with urine specimens by using low-speed centrifugation and monoclonal antibody to an early antigen. J Clin Microbiol 1984;19:917-9.

2. Belitsky P, MacDonald AS, Cohen AD, et al. Comparison of antilymphocytic globulin and continuous iv cyclosporin A as induction immunosuppression for cadaver kidney transplants: A prospective randomized study. Transplant Proc 1991:23:999-1000.

3. Betts RF, Freeman RB, Douglas RG, et al. Transmission
Certainly, additional prophylactic measures appear indicated in OKT3-treated patients. Ganciclovir, a more effective agent than either acyclovir or CMV-HIG in treating established CMV disease (9), would appear to be an attractive option. Recent reports $(25,26)$ have shown beneficial effects when used prophylactically in bone marrow transplantation, albeit at the cost of side effects such as leukopenia and thrombocytopenia $(15,16,25,26)$.

Acute rejection and graft loss are known to be more frequent in association with CMV disease $(3,6,8,27)$, perhaps related to regulation of major histocompatibility complex class II antigens by viral-released gamma interferon (27). This increased graft loss was confirmed in our study, in which patients with CMV disease had a one-year graft survival of only $62 \%$ versus $90 \%$ for those without CMV disease. With only one CMV-related death, however, patient survival was not reduced. Overall, graft and patient survival were comparable at one and three years between groups, with better graft survival in $\mathrm{D}+/ \mathrm{R}$ - recipients. This is consistent with recent data from the Collaborative Transplant Study (28), but contrasts with previously published studies $(6,29)$ in which graft survival was significantly reduced in $\mathrm{D}+/ \mathrm{R}-$ kidney transplant recipients. A higher rate of clinical CMV disease in unprotected patients may explain the lower graft survival in the latter studies, although surprisingly, Opelz (28) found that the survival figures were only marginally improved by the use of prophylaxis against CMV infection.

In summary, the routine use of CMV-HIG in combination with low dose oral acyclovir allows CMV-negative recipients to be safely transplanted with kidneys from CMV-positive donors. The incidence of early morbidity and graft loss due to CMV infection was similar to that in recipients who were CMV-positive before grafting.

In addition, the use of a low does acyclovir regimen (600 $\mathrm{mg} /$ day) appears effective in reducing the incidence of CMV disease in lower risk CMV-positive recipients. Despite the use of CMV-HIG and/or acyclovir, the use of OKT3 for steroid-resistant rejection was a major risk factor for CMV disease with increased morbidity and graft loss. Additional prophylactic measures seem necessary in this group. Short term ganciclovir appears to only delay the appearance of disease, at least in cardiac recipients (30), but different drug regimens may overcome this.

of cytomegalovirus infection with renal allografts. Kidney Int 1975;8:385-92.

4. Rocha E, Campos HH, Rovzioux C, et al. Cytomegalovirus infections after kidney transplantation: Identical risk whether donor or recipient is the virus carrier. Transplant Proc 1991;23:2638-40.

5. Weir MR, Irwin BC, Maters AW, et al. Incidence of cytomegalovirus disease in cyclosporin treated renal transplant recipients based on donor/recipient pretransplant immunity. Transplantation 1987:43:187-93.

6. Rubin RH, Tolkoff-Rubin NS, Oliver D, et al. Multi-centre seroepidemiologic study of the impact of cytomegalovirus 
infection on renal transplantation. Transplantation 1985;40:243-9.

7. Snydman DR, Werner BC, Heinze-Lacey B, et al. Use of cytomegalovirus immune globulin to prevent cytomegalovirus disease in renal transplant recipients. N Engl J Med 1987;317:1049-54.

8. Lewis RM, Johnson PC, Gidden D, et al. The adverse impact of cytomegalovirus infection on clinical outcome in cyclosporin prednisone treated renal allograft recipients. Transplantation 1988;45:353-9.

9. Dunn DL, Mayoral JL, Gillingham KT, et al. Treatment of invasive cytomegalovirus disease in solid organ transplant recipients with ganciclovir. Transplantation 1991;51:98-106.

10. Stratta RJ, Shaefer MS, Cushing KA, et al. Successful prophylaxis of cytomegalovirus disease after primary CMV exposure in liver transplant recipients. Transplantation 1991;51:90-7.

11. Winston DJ, Ho WG, Lin $\mathrm{CH}$, et al. Intravenous immune globulin for prevention of cytomegalovirus infection and interstitial pneumonia after bone marrow transplantation. Ann Intern Med 1987:106:12-8.

12. Balfour HH, Chace BA, Stapleton JT, at al. A randomized, placebo-controlled trial of oral acyclovir for the prevention of cytomegalovirus disease in recipients of renal allografts. N Engl J Med 1989;320:1381-7.

13. Schlech WF III, Meagher N, Cohen AD, Belitsky P, MacDonald AS, LeBlanc JC. A randomized double-blind placebo controlled trial of oral acyclovir in renal allograft recipients. Can J Infect Dis 1993;4:84-8.

14. Matthews T, Boehme R. Antiviral activity and mechanism of action of ganciclovir. Rev Infect Dis 1988;10:5490-4.

15. Schmidt GM, Kovacs A, Zaia JA, et al. Ganciclovir/ immunoglobulin combination therapy for the treatment of human cytomegalovirus-associated interstitial pneumonia in bone marrow allograft recipients. Transplantation 1988:40;905-7.

16. Reed EC, Bowden RA, Dandliker PS, et al. Treatment of cytomegalovirus pneumonia with ganciclovir and intravenous cytomegalovirus hyperimmune globulin in patients with bone marrow transplants. Ann Intern Med 1988; 109:785.

17. Najarian JS, Fryd DS, Strand M, at al. A single institution, randomized prospective trial of cyclosporin versus azathioprine antilymphocyte globulin for immunosuppression in renal transplant recipients. Ann Surg 1985;201:142-8.

18. D'Alessandro AM, Pirsch JD, Stratta RJ, et al. OKT3 salvage therapy in a quadruple immunosuppressive protocol in cadaveric renal transplantation. Transplantation 1989;47:297-300.

19. Hibberd PL, Tolkoff-Rubin NE, Cosimi AB, et al. Symptomatic cytomegalovirus disease in the cytomegalovirus antibody seropositive renal transplant recipient treated with OKT3. Transplantation 1992;53:68-72.

20. Chiu A, Landsberg D, Cameron EC, Manson ADC, Shackleton C. The effect of induction ALG(MALG) on the outcome of steroid resistant rejection treated with OKT3 in renal transplant patients. Transplant Proc 1991:23:1039-40.

21. Light JA, Khawand N, Ali A, Brems W, Aquino A. Comparison of Minnesota antilymphycytic globulin and OKT3 for induction of immunosuppression in renal transplant patients. Transplant Proc 1989;21:1738-40.

22. Deeb GM, Bolling SF, Steimle CN, et al. A randomized prospective comparison of MALG with OKT3 for rescue therapy of acute myocardial rejection. Transplantation 1991;51:180-3.

23. Carreno M, Yang WC, Esquenazi V, et al. OKT3 induction via idiotypic networks of mirror image immunosuppressive antiimmunoglobulins in renal transplant recipients. Transplantation 1990:49:408-15.

24. Yang WC, Carreno M, Esquenazi V, et al. Evidence that antibodies to cytomegalovirus and the T-cell receptor (TCR)/CD3 complex may have common ligands. Transplantation 1991:51:490-8.

25. Schmidt GM, Horak DA, Niland JC, et al. A randomized, controlled trial of prophylactic ganciclovir for cytomegalovirus pulmonary infection in recipients of allogeneic bone marrow transplants; The City of Hope-Stanford Syntex CMV Group. N Engl J Med 1991;324:1005-11.

26. Goodrich JM, Mori M, Gleaves CA. Early treatment with ganciclovir to prevent cytomegalovirus disease after allogeneic bone marrow transplantation. N Engl J Med 1991;355:25.

27. Von Willebrand E, Pettersson E, Ahonen J, Hayry P. CMV infection, class II antigen expression and human kidney allograft rejection. Transplantation 1986;42:364-7.

28. Opelz G. Collaborative Transplant Study Newsletter 1991 ;Aug.

29. Metselaar HJ, Ploeg RJ, Van Loon AM, et al. Prevention of CMV infection by screening for CMV antibodies in renal allograft recipients and their blood and kidney donors. Scand J Infect Dis 1988;20: 135-9.

30. Merrigan TC, Renlund DG, Keay S, et al. A controlled trial of ganciclovir to prevent cytomegalovirus disease after heart transplantation. N Engl J Med 1992;326:1182-6. 


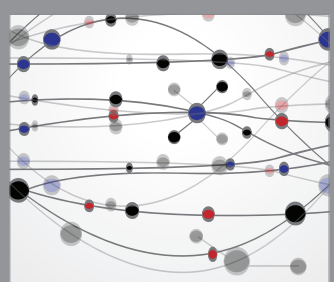

The Scientific World Journal
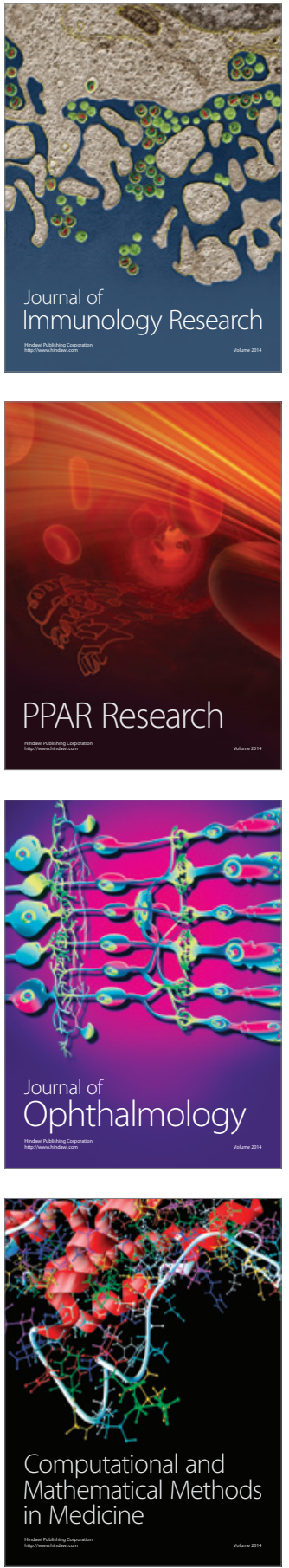

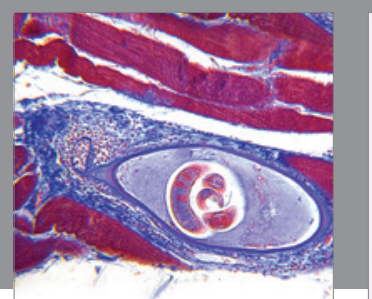

Gastroenterology Research and Practice

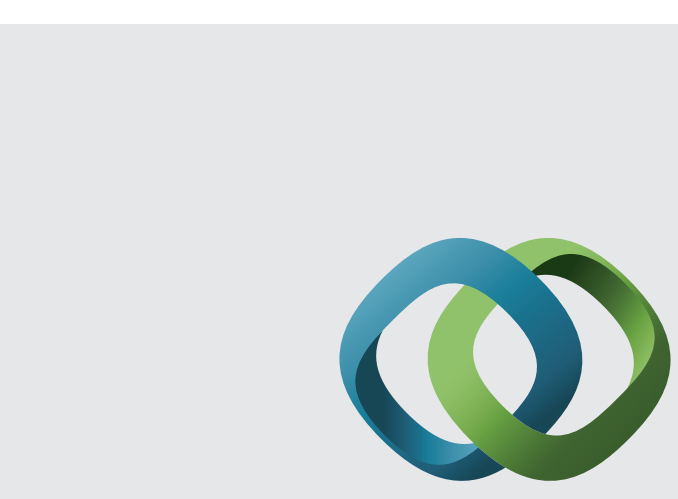

\section{Hindawi}

Submit your manuscripts at

http://www.hindawi.com
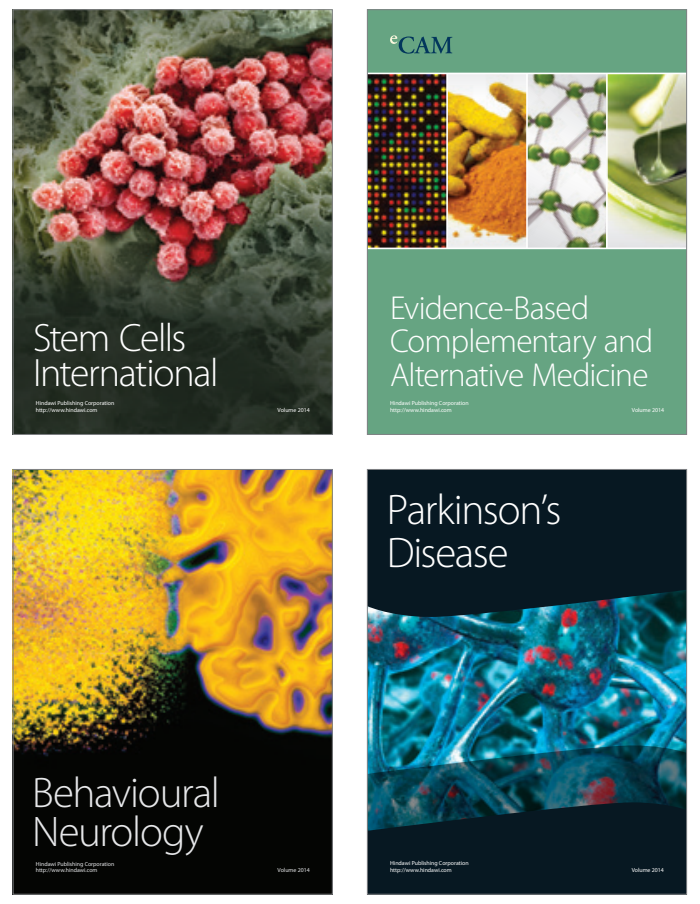
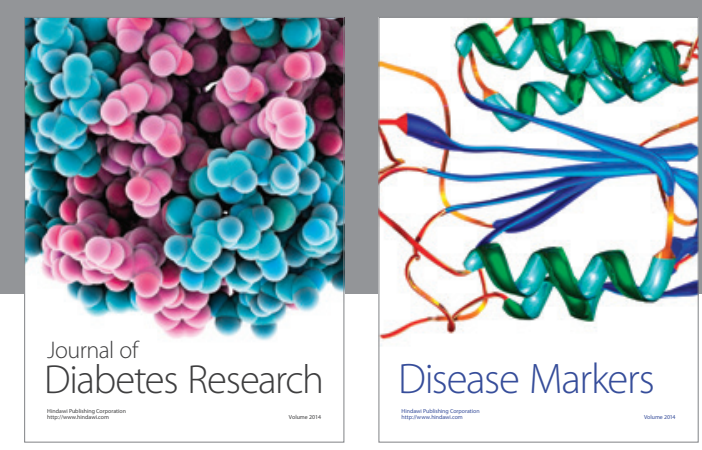

Disease Markers
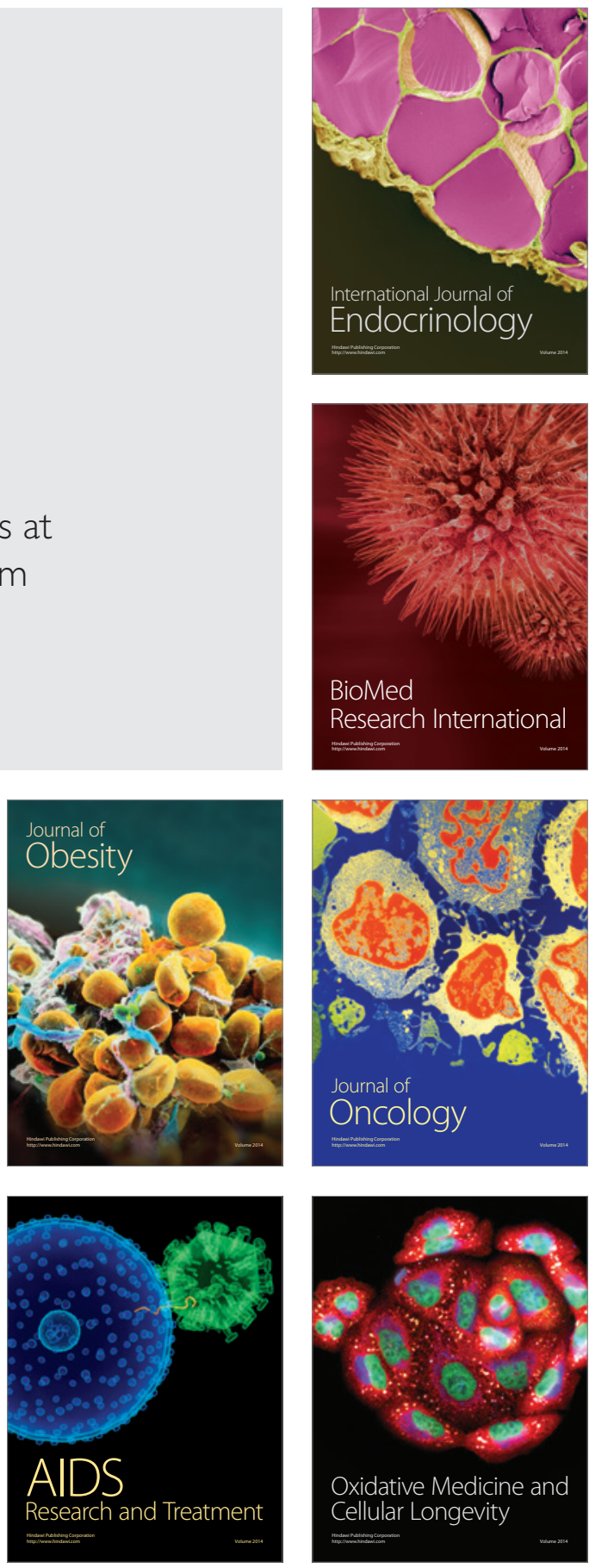